\title{
Selective Adhesion of Nanoparticles to Inflamed Tissue in Gastric Ulcers
}

\author{
Saad Hassani, ${ }^{1}$ Yann Pellequer, ${ }^{1}$ and Alf Lamprecht ${ }^{1,2,3}$
}

Published online March 13, 2009

The family name of one of the authors_-HASSANI—is misspelled in the published article. Please note the correct spelling as shown in this erratum.

\footnotetext{
${ }^{1}$ Laboratory of Pharmaceutical Engineering (EA3924), School of Medicine and Pharmacy, University of Franche-Comté, Place Saint Jacques, 25000, Besançon, France.

${ }^{2}$ Laboratory of Pharmaceutical Technology and Biopharmaceutics, Institute of Pharmacy, University of Bonn, Gerhard-Domagk-Str. 3, 53121, Bonn, Germany.

${ }^{3}$ To whom correspondence should be addressed. (e-mail: alf.lamprecht@univ-fcomte.fr)
}

The online version of the original article can be found at: doi:10.1007/s11095-009-9834-1 of the article with published errors. 